\title{
Gobernanza de la pandemia del covid-19 y modelos de
}

\section{gestión: ¿Hacia un nuevo tipo de vínculo sociedad-Estado?}

\author{
Josep Pont Vidal ${ }^{1}$ \\ ${ }^{1}$ Universidad Federal de Pará (UFPA), Belém - PA, Brasil
}

La pandemia causada por el Covid-19 ha impulsado, de manera urgente y no planificada, diferentes orientaciones o modelos de gobernanza de la pandemia. Los gobiernos han propuesto diferentes modelos $u$ orientaciones de combate a la pandemia, con resultados no concluyentes. Estos modelos y las premisas que los subyacen no son solo respuestas rápidas a una situación contingente e hipercompleja en la situación sanitaria, sino que corresponden a la existencia de racionalidades, decisiones y planificación de modelos de administración y gestión y su vínculo con el Estado. A partir de un contexto de hipercomplejidad, describimos una aproximación a los modelos de gestión de la pandemia de Suecia, Alemania y España, principalmente. Con base en las reflexiones sobre su gestión, abrimos un análisis sobre las orientaciones en la reconfiguración futura del Estado y su relación con la sociedad y la administración y gestión pública y los impactos políticos ya visibles.

Palabras clave: administración y gestión pública, pandemia covid-19, Unión Europea

\section{Governança dos modelos de pandemia e gestão da covid-19: Rumo a um novo tipo de} vínculo sociedade-estado?

A pandemia causada pela covid-19 gerou, de maneira urgente e não planejada, diferentes orientações ou modelos de governança da pandemia. Os governos propuseram diferentes modelos ou diretrizes para combater a pandemia, com resultados inconclusivos. Esses modelos e as premissas subjacentes a eles não são apenas respostas rápidas a uma situação contingente e hipercomplexa para responder à situação de saúde, mas correspondem à existência de racionalidades, decisões e planejamento dos modelos de administração e gestão e sua ligação com o Estado. De um contexto de hipercontingência, descrevemos uma abordagem para os modelos de gerenciamento de pandemia da Suécia, Alemanha e Espanha, principalmente. A partir das reflexões sobre sua gestão, abrimos uma análise sobre as orientações para a futura reconfiguração do Estado e sua relação com a sociedade, a administração e a administração pública e os impactos políticos já visíveis.

Palavras-Chave: administração e gestão pública, pandemia covid-19, União Europeia 
Governance of the Covid-19 pandemic and management models: towards a new type of society-state link?

The pandemic caused by the Covid-19 has prompted, in an urgent and unplanned manner, different orientations or governance models of the pandemic. Governments have proposed different models or guidelines to combat the pandemic, with inconclusive results. These models and the premises that underlie them, are not only quick responses to a contingent and hyper-complex situation to respond to the health situation, but correspond to the existence of rationalities, decisions and planning of Administration and management models and their link with the state. From a context of hyper contingency, we describe an approach to the pandemic management models of Sweden, Germany and Spain mainly. Based on the reflections on its management, we open an analysis on the orientations in the future reconfiguration of the State and its relationship with society and the Administration and public management, and the already visible political impacts.

Key words: public administration and management, covid-19 pandemic, European Union 


\section{Introducción y contextualización}

La pandemia causada por el Covid-19 ha impulsado, de manera urgente y no planificada, diferentes orientaciones o modelos de gobernanza de la pandemia. Estos modelos y las premisas que los subyacen no son solo respuestas rápidas a una situación contingente e hipercompleja para dar respuesta a la situación sanitaria creada, sino que corresponden a la previa existencia de racionalidades, planificación, inversiones y, en el caso de este artículo, a diferentes modelos de administración y gestión y a su vínculo con el Estado. En un contexto contingente, exponemos una aproximación a los modelos de gestión de la pandemia de tres países: Suecia, Alemania y España, principalmente. En base a las reflexiones sobre su gestión, abrimos un análisis sobre los impactos en la reconfiguración y orientación del Estado y su relación entre la sociedad y la administración y gestión pública.

En la situación creada por la pandemia, las administraciones públicas han tenido que adaptarse a unas condiciones muy inestables en un espacio de tiempo muy limitado: toma de decisiones constantes y rápidas, reformulación rápida de métodos y aplicación de tecnologías todavía insuficientemente expandidas y aplicadas, nuevos tipos de atención masiva de los ciudadanos, elevado absentismo por cuestiones de enfermedad y contagio de muchos funcionarios públicos, etc. A esta nueva situación dinámica, hay que añadir las medidas que los gobiernos de todo el mundo tuvieron que tomar referentes a las restricciones de las libertades constitucionales: confinamiento obligatorio de la población, restricción de movimientos, vigilancia y control masivos por medio de las posibilidades de Big-data, medidas coactivas, etc.

Cada gobierno ha reaccionado frente a esta contingencia inesperada de diferentes maneras y estrategias. Ante la gravedad de la situación, algunos gobiernos se han prácticamente adelantado a los impactos, otros han tardado unos días o semanas con consecuencias catastróficas para el sistema de salud (Italia y España, por ejemplo), mientras otros han optado por estrategias de combate y control diferentes como el confinamiento voluntario (Suecia). Las decisiones que han motivado estas estrategias no se deben a situaciones improvisadas, sino que corresponden a modelos de gestión ya existentes en cada gobierno, modelos de selección meritocráticos para los cargos de responsabilidad y dirección, y en definitiva el tipo de relación entre la administración pública y el Estado.

Partimos de la suposición de que el éxito en la gestión y control de la pandemia, o solo la gestión reactiva e improvisada de los impactos ha sido consecuencia de diferentes 
causas vinculadas con los tipos de relación del trípode administración-sociedad-Estado: planificación e inversiones en el sistema de salud nacional, capacidad profesional y expertise de los responsables políticos de salud y control de enfermedades, extensión de la coproducción de servicios, incremento de la cooperación público-privada, aunque relegando "lo público" (en la versión conservadora) y en la extensión y reducción de las responsabilidades del Estado. Estas tendencias no son nuevas, sino que corresponden a acciones y estrategias ya iniciadas en los últimos años. Este proceso ha tenido lugar en un contexto de hipercomplejidad, es decir, con la emergencia de incontables variables que requieren una selección por parte del observador, y en la que ya se insertan unas nuevas y cambiantes relaciones entre la sociedad y el Estado. Así pues, se está configurando definitivamente una nueva relación entre la sociedad y el Estado y, en consecuencia, una nueva relación entre la política y la administración pública. ¿Cómo afecta y cómo se manifiesta esta nueva relación?

El artículo tiene el objetivo de intentar responder de forma inicial a dos cuestiones fundamentales: primera, qué modelos de gestión se han implementado en países de la Unión Europea; y segunda, a qué modelos de relación o vínculo entre la administración y el Estado corresponde. Hemos limitado y organizado este escrito en tres apartados. En el primer apartado abordamos el vínculo de la gobernanza con la contingencia y el riesgo, cuyos impactos en la administración pública han sido escasamente analizados. En el segundo exponemos modelos de gestión en diversos países de la Unión Europea. En el tercer apartado, describimos los cambios y las tendencias subyacentes que corresponden de alguna forma con el papel del Estado y sus impactos en las administraciones públicas. Toda reforma no es casual, sino que responde a unos intereses, modelos y actuaciones por parte del poder político. Esbozamos los modelos en que se deslumbra la relación entre Estado y sociedad y, en consecuencia, entre Estado y administración. No es el objetivo de este artículo, hacer un análisis sobre las decisiones tomadas por los respectivos gobiernos. Tampoco se tiene la pretensión de responder las cuestiones planteadas de forma conclusiva dadas las incertidumbres existentes. En el plano metodológico se ha recurrido a informaciones publicadas en periódicos, ministerios de salud nacionales y agencias de salud internacionales, limitando temporalmente entre los meses de febrero y mediados de junio de 2020.

\section{Hipercomplejidad, contingencia y riesgo}

Algunas de las decisiones que toman los gobiernos o el poder político, pueden no ser 
necesarias, pero al mismo tiempo, sus consecuencias tampoco son previsibles. La causa de los fenómenos no puede ser demostrada ni negada de manera definitiva. Las probabilidades estadísticas demuestran esta hipótesis. Así, contingentes son las proposiciones que no son necesariamente verdaderas ni necesariamente falsas, aunque surja una posibilidad real de que sucedan. La incerteza caracteriza estas situaciones que se manifiestan en actuaciones frente a desastres naturales o de origen humano. En el caso de la pandemia causada por el Covid-19 y de la preparación y prevención sanitaria de las sociedades, es evidente que la situación encontró a todos los países desprevenidos, aunque disponer de un sistema de sanidad más extenso y preparado no era una tarea imposible, su existencia ha dependido siempre de decisiones políticas y administrativas previas o durante la pandemia. En el caso de las sociedades modernas actuales, que son en general hipercomplejas y formadas por una extensa y densa organización político-administrativa y jurídica en múltiples niveles, es necesario abordarlas en la perspectiva de la contingencia y del riesgo.

Estas sociedades se orientan cada vez más a un tipo de articulaciones, convenciones y mediaciones hacia sistemas e interacciones altamente sofisticadas En el caso de la pandemia, son las comunicaciones emitidas entre el ámbito sanitario, el científico y el económico, han resultado asimétricamente contrapuestas o no aceptadas mutuamente. En estas sociedades la articulación entre los diferentes niveles de gobierno y de las instituciones, su funcionamiento, la gestión de las demandas y emergencia de conflictos, son cada vez más caracterizados por largos procesos hipercomplejos en muchas ocasiones con intereses diametralmente opuestos, como se ha demostrado en España en la gestión de la pandemia entre los diferentes niveles de gobierno central y autonómico de Cataluña y el País Vasco.

La pandemia del Covid-19 ha puesto de manifiesto la hipercomplejidad en todas sus dimensiones: paradojas entre la economía, la salud y la ciencia, y en las decisiones en diferentes niveles de gobierno en todos los países (ya sean federales o descentralizados), diversas lógicas de combate y confinamiento (y sus irracionalidades). También se han evidenciado las disfunciones en las estrategias de combate a la pandemia entre las decisiones gubernamentales, la articulación multinivel y entre los gobiernos y la Organización Mundial de la Salud, y entre los estados de la Unión Europea, en las primeras semanas de abril de 2020.

\subsection{Hipercomplejidad, Administración y gestión pública}


Todavía es reciente la idea de que los procesos de toma de decisiones, la gestión en las políticas públicas, los procesos administrativos y burocráticos de la administración pública son procesos intrincados. A diferencia de otras ciencias sociales, como es la economía, es todavía reciente la utilización de las ideas de las teorías sobre la complejidad y su utilización en las observaciones de la administración y gestión pública. Los enfoques vinculados con la complejidad (o hipercomplejidad) y los enfoques evolutivos y sistémicos en la perspectiva autorreferencial han recibido poca atención analítica y empírica (VIDAL, 2019). Consideramos en el escenario descrito de la pandemia de Covid-19 como de hipercompejidad, en que podemos caracterizar la emergencia de multiplicidad de variables (cualitativas y cuantitativas) sobre las cuales es necesario seleccionar y que han tenido sus impactos en los modelos de gobernanza multinivel aplicados por los gobiernos ${ }^{11}$. El concepto ha sido utilizado y analizado por diversos estudiosos de la teoría sistémica (KNOdT, 1995, p. XVIII; LA CouR; PhILIPPoulos, 2013; ANGelL; De METRIS, 2010, p. 187) y en el contexto del tema de este escrito se refiere a los factores contingentes y las múltiples variables que intervinieron durante la pandemia del Covid-19.

¿Cómo puede contribuir la teoría sistémica o el punto de partida de la complejidad para aumentar la compresión de este abrupto fenómeno y sus inherentes peligros, con las propuestas de resolución de problemas en la administración y la gestión pública respecto a la gestión de la pandemia del Covid-19? En ámbitos económicos específicos (gestión hospitalaria, empresarial etc.), las publicaciones han hecho hincapié en el potencial de la teoría de la complejidad para abordar el desarrollo de políticas (TAIT; RICHARDSON, 2009), se cuestiona el papel de los expertos de políticas y su pretendida expertise, "autoridad" y "experiencia" de los modelos económicos tradicionales, al tratarse de un simple reduccionismo, al ignorar el complex thinking.

La teoría de sistemas y de los procesos de adaptación mutua entre ellos, es una posibilidad de observación y análisis. Se parte del presupuesto de los principios de la good governance y de la capacidad dinámica de autoorganización como una característica permanente en evolución en los procesos emergentes. Aunque no se asuma la lógica de la capacidad operativa autónoma de un sistema, y por lo tanto de crear sus propias estructuras, estos procesos se forman a partir de eventos, fenómenos de acción e interacción colectiva, los cuales contribuyen a formar una estructura institucional.

\footnotetext{
${ }^{11}$ Niklas Luhmann en sus escritos se refiere indistintamente a "complejidad" y "hipercomplejidad", y define esta última como la ausencia de un padrón moral en la sociedad. Véase aquí: N. Luhmann, [1984] 2016; 2006.
} 
En los sistemas de salud y de funcionamiento hospitalario la auto organización, o capacidad de auto gestionarse en todos los niveles (elección de compras de material, elección de modelos de gestión privados etc.), surge de la capacidad de libre elección y acción de las personas participantes y las organizaciones en el sistema político, económico o sanitario. No obstante, la interacción, como veremos en el sistema sanitario (con opciones asimétricas de compras de material en España, entre el gobierno central y los autónomos) también puede obstruir estos procesos, por lo que es necesario un tipo de comprensión de la coordinación (multinivel), ya que la integración difiere de las ideas convencionales sobre la simple adaptación mutua. La sincronización entre los participantes o las organizaciones (entre los niveles municipal, regional y central) presupone que una estructura es insuficiente para estimular la integración, aunque exista un contexto de diversidad institucional (político y/o jurídico) dentro del cual los límites cambian constantemente, lo que requiere que sean establecidas nuevas interconexiones entre ellos.

\subsection{Contingencia y riesgo en el contexto de la pandemia Covid-19}

La Organización Mundial de la Salud (OMS) ya había publicado en el año 2019 (OMS-GPMB, septiembre 2019) un informe en el que advertía la posibilidad de una pandemia mundial causada por un virus desconocido y la necesidad de que los gobiernos se prepararan para esta situación. El riesgo de la eclosión de una pandemia de tal magnitud y profundidad, con efectos tan devastadores, no fue asumida por ningún país occidental. Ya con la eclosión del Covid-19 en Wuhan el mes de enero del 2020, la OMS minimizó la posibilidad de una pandemia de alcance mundial. En un primer momento, la OMS admitió el 27 de enero, un error en la divulgación del riesgo global del nuevo coronavirus. Inicialmente esta organización calificó el riesgo de "moderado", siendo rectificado más tarde por "alto", y, posteriormente, que el riesgo era "muy alto en China, alto regionalmente y alto globalmente". La imperceptibilidad de los peligros, su supranacionalidad, la "expropiación ecológica" y el paso de la normalidad a la absurdidad fueron diagnosticados por Beck ([1986]1998), en la ocasión del accidente nuclear de Chernóbil en 1986. La contingencia estuvo presente en las decisiones iniciales de la OMS: ¿Por qué no fue informada por el gobierno chino del elevado riesgo? ¿Era imposible un riesgo "moderado”, o "alto”? ¿Sería posible que su expansión e infección fuera tan rápida?

Como la contingencia, el riesgo y el peligro constituyen una secuencia dinámica y continua, algo que ha quedado claro en la gestión del coronavirus. Contingencia, en la perspectiva que presentamos aquí, o sea, aquello que no es necesario ni imposible, pero 
que puede existir siempre, comporta necesariamente riesgo, y el riesgo comporta a su vez peligro. Además de los predicados ontológicos "ser" y "no ser", la contingencia también implica un tercer valor, a saber, la "imposibilidad de determinación". La "era de incertidumbre", como se ha demostrado durante la pandemia, es una versión particular de la sociedad moderna, cuyo atributo determinante es la contingencia. En las condiciones modernas, las necesidades y las imposibilidades ya no proporcionan el marco ordenado del mundo. Ya no existen formas socialmente necesarias para la limitación recíproca de los diversos componentes de la sociedad o incluso para la coherencia social del conjunto. Se acepta que todo lo que se supone puede ser diferente, y que cualquier cosa, aunque no todo de una vez, se puede redefinir y cambiar a través de la comunicación. La sociedad moderna es una sociedad que abarca las contingencias como ninguna otra antes. Si bien las necesidades e imposibilidades se aceptan por razones de tiempo, en este tipo de sociedad, en consonancia con su aceptación de las contingencias, se caracteriza sobre todo por atributos débiles requeridos (seguridad, planificación, control de laboratorios biológicos entre otros factores) en el sentido de propiedades emergentes inicialmente indeterminables, altamente improbables y frágiles.

Debería ser obvio que, en las condiciones de las sociedades contemporáneas, tanto la ciencia como la política, y su relación entre sí, ya no pueden concebirse en términos de necesidad, sino que deben analizarse en términos de estas propiedades improbables y frágiles emergentes de sociedad. Al mismo tiempo, sin embargo, debe recordarse que, en estas condiciones, nada se considera tampoco imposible: ¿Qué gobierno podría afirmar en enero del 2020, que se avecinaba una revolución mundial que abarcaría todos los ámbitos, tecnológica, económica, social, de consumo, de tiempo libre, académica, solo cuatro semanas más tarde? ¿Qué consultoría podría anticipar que esta revolución haría caer gobiernos y ministros en pocas semanas? ¿Qué estudio podría anticipar que el concepto de viajes de larga distancia cambiaría radicalmente? ¿Quién podría afirmar empíricamente la efectividad del "efecto mariposa", que un simple movimiento pudo afectar a una sociedad a 10.000 kilómetros de distancia?

El riesgo está presente en todos los ámbitos de la vida cotidiana organizacional y en las organizaciones sanitarias en particular: en su gestión, planificación, toma de decisiones, inversiones, etc. Surge la pregunta: ¿Qué es el riesgo? Las diferentes corrientes en la filosofía y en las ciencias sociales le han atribuido diversos significados. En la tradición racionalista ha sido considerado como producto de una decisión que según sus impactos posteriores (negativos) se hubieran podido prever o evitar. Aquí se trata de un cálculo temporal con el horizonte de un futuro incierto y cuyos impactos podrían ser evitados. 
Pueden ser aceptadas situaciones de riesgo que lo contemplen, siempre y cuando esté justificada la posibilidad de que ocurra (construcción de grandes represas, empresas contaminantes, experimentación con nuevos virus, etc.). Esta ha sido la argumentación imperante. Niklas Luhmann $([1984] 2016)$ ha cuestionado el concepto tradicional de contingencia por ser limitada, puesto que sólo puede describir riesgos en sus aspectos cuantitativos y probabilísticos y los analiza básicamente en el sistema económico y científico.

El análisis y observación del riesgo en la diferenciación funcional posibilita utilizar simultáneamente la observación elemental (basada de datos estadísticos) y la observación de segundo grado (basada en las selecciones del observador). La observación de primer grado es el mundo real $y$, por lo tanto, es limitada al poder solamente identificar cuantitativamente los posibles riesgos. Con la utilización del concepto binario riesgoseguridad, se tratan de observaciones sólo para garantizar la seguridad, para la cual es necesario más y mejor tipo de información. Por esto propone que la teoría debe ser orientada a la observación de segundo orden. Se trata de un fenómeno de "contingencia múltiple" (LUHMANN, 2016), o sea, permite y ofrece abordarlo desde diferentes perspectivas por diferentes observadores. Aquí el problema reside en que el riesgo es algo que es descrito como similar por diferentes observadores. La consecuencia es que genera informaciones muy diversas entre ellos. En este punto, propone la diferenciación entre riesgo y peligro. Mientras que el riesgo se refiere al caso en que el desafío es consecuencia de la decisión, con el peligro los posibles daños son provocados externamente, es decir atribuido al entorno del sistema. La observación de segundo grado permite establecer la distinción entre quienes deciden qué son los riesgos y quienes son los afectados.

\section{La gestión de la pandemia en los países de la Unión Europea}

La pandemia del covid-19 ha cogido a los países de la Unión Europea, como todas las sociedades y gobiernos del mundo por sorpresa. Las reticencias iniciales a una mayor cooperación no se han solucionado definitivamente. Las propuestas de hacer mutuos los costos de la pandemia o de "eurobonos" sugeridas por los presidentes de España y de Italia para superar la crisis económica han encontrado con fuertes resistencias entre los países nórdicos, en especial Dinamarca, Holanda y Austria ${ }^{12}$.

Ha sido común entre los países de la UE que durante la pandemia el foco de

12 CAIXABANK, Álvaro Leandro y Adriá Morron, Políticas económicas frente a la COVID-19: ¿se romperán las fronteras de lo imposible? Disponible en: https://www.caixabankresearch.com/politicaseconomicas-frente-la-covid-19-se-romperan-las-fronteras-de-lo-imposible 
contagio más frecuente haya sido encontrado en las residencias de ancianos. Este trágico fenómeno se ha registrado en prácticamente todos los países. Solo en Suecia, la Agencia de Salud Pública logró demostrar por medio de las estadísticas que al menos el $40 \%$ de las muertes en la región urbana de Estocolmo, el epicentro de la epidemia en este país, se produjeron en instituciones para ancianos y en asilos para tercera edad. El mismo fenómeno se ha reproducido en Francia, Italia, Gran Bretaña, España, y en menor medida en los países nórdicos y Alemania. En las Comunidades de Madrid y Cataluña (14.900 en total, aproximadamente el $40 \%$ de fallecimientos se produjo en estos centros) ${ }^{13}$.

De manera similar a la Gran Recesión que azotó los países de la EU entre los años 2008-2010, aunque sus impactos no han sido superados, en especial en los países de la cuenca mediterránea, la crisis del coronavirus ha demostrado que la UE no tiene un mecanismo de gobernanza que pueda garantizar la solidaridad entre sus miembros. La pandemia del Covid-19 y la solidaridad entre sus estados es una cuestión que será mantenida en el futuro. No se ha dispuesto de mecanismos que impulsen a los países miembros a responder de forma conjunta, o al menos coordinada.

\subsection{Suecia}

A diferencia de los demás países nórdicos (Dinamarca y Noruega) que adoptaron la estrategia de semi-confinamiento, el gobierno de Suecia descartó la posibilidad de aislar a su población por considerar que las medidas drásticas no eran lo suficientemente eficaces como para justificar su impacto en la sociedad. Desde el inicio de la pandemia, Suecia ha intentado en las primeras semanas una estrategia diferenciada respecto al resto de países de la Unión Europea y, con pocas excepciones en el mundo. Se ha informado a la población sobre los peligros, el gobierno ha realizado y recomendado el distanciamiento social, aunque no ha impuesto el confinamiento total de la población, sino una especie de semi confinamiento, pues el gobierno consideró que las medidas drásticas no eran eficaces para frenar los impactos de todo tipo en la sociedad. Las universidades y colegios han continuado normalmente, al igual que la vida en las terrazas, parques, bares y cafés. Se ha partido de la premisa cultural de este país y de la responsabilidad individual, en un país con una población de alrededor de diez millones de habitantes. En Suecia la ciencia ha mantenido un diálogo entre el ámbito económico y el cultural, en el que la ciencia vinculó la constatación

\footnotetext{
${ }^{13}$ RTVE, Radiografía del coronavirus en residencias de ancianos: más de 19.400 muertos con Covid19 o síntomas compatibles, 15 junio 2020. Disponible en: https://www.rtve.es/noticias/20200615/radiografia-del-coronavirus-residencias-ancianosespana/2011609.shtml
} 
histórica y empírica del país con epidemias pasadas para abordar las medidas de lucha contra la pandemia de Covid-19.

En un informe de $\mathrm{HSBC}^{14}$, se destacan tres características demográficas del país que han permitido también amortiguar el impacto social y económico del coronavirus: 1) Más de la mitad de los hogares suecos se componen únicamente de una persona, lo que facilita el distanciamiento social; 2) Más personas trabajan desde la modalidad domiciliaria que cualquier otro lugar en Europa; 3) Todos los hogares cuentan con acceso a internet para el desarrollo de sus actividades laborales.

En Suecia, la gestión de las situaciones de crisis se confía a las agencias especializadas, (Junta Nacional de Salud y Bienestar, Agencia Sueca de Contingencia Civiles, MSB) no siendo el gobierno quien ha tomado las decisiones. La Agencia Nacional de Salud (Folkhälsomyndigheten tiene la responsabilidad del desarrollo y la actualización de la expertise, así como busca difundir el conocimiento sobre la medicina de desastres y la preparación para emergencias con el fin de proporcionar asistencia al Sistema de Salud y servicios sociales en tiempos de emergencia y gestión de desastres. El gobierno ha encargado a la Junta que coordine y prepare la disponibilidad de medicamentos y suministros médicos según sea necesario en un estado de alerta reforzado. La estrategia por la que se optó para la contención del virus no fue tanto frenarlo en seco o permitir una "inmunidad de rebaño" (o pasaporte inmunológico, como inicialmente propuso el Primer ministro Boris Johnson en Gran Bretaña), cuando la mayoría de la población adquiere anticuerpos. La Agencia Nacional de Salud ha partido de la hipótesis de una cultura de distancia social "natural" entre la población. El consultor de la Agencia de Nacional Salud, Johan Giesecke expone el principal argumento ${ }^{15}$ :

Nosotros, o el gobierno sueco, decidimos en inicio de enero que las medidas que debemos tomar contra la pandemia deben ser basadas en evidencias. Cuando se empieza a analizar las medidas que están siendo tomadas ahora por diferentes países, se percibe que muy pocas de ellas tienen un sustento de evidencia (...) Pero sabemos de una que es conocida desde hace 150 años o más, que consiste en lavar sus manos, esto es bueno para uno mismo y para los otros cuando se está en una epidemia. Pero el resto, el cierre de fronteras,

\footnotetext{
${ }^{14}$ HSBC Global Research, 2020. Disponible en: https://www.research.hsbc.com/C/1/1/320/gjvcpRH

15 Pfarma.com.br, Fabio Reis, 14 mayo 2020, Estudo de caso: Suécia e o novo coronavírus, disponible en: https://pfarma.com.br/coronavirus/5612-suecia-covid19.html
} 
cierre de escuelas, distanciamiento social... casi no existe ciencia por detrás de esto (REIS, 2020).

No obstante, esta estrategia ha comportado un elevado número de fallecimientos y el colapso de la sanidad, aunque el sistema no ha llegado en ningún momento al colapso. Las únicas medidas importantes fueron prohibir las reuniones o grupos de más de 50 personas, y las visitas a los asilos de ancianos. Por lo demás, el gobierno hizo un llamamiento a la "conciencia cívica", pidiendo a todos que "asumieran sus responsabilidades" y que siguieran las recomendaciones en materia de salud. Ante un aumento de casos, no fue hasta el 16 de abril, que el Parlamento ha concedido poderes especiales al gobierno para que decretara medidas más restrictivas. Con estos poderes el gobierno posee la autonomía de poder actuar rápidamente en caso necesario con medidas como cierres de puertos, escuelas o centros deportivos o recreativos ${ }^{16}$.

Sin embargo, la estrategia del gobierno no ha sido libre de críticas por parte del sistema científico. Para Bo Lundbäck, profesor de epidemiología de la Universidad de Gotemburgo (oeste): "las autoridades y el gobierno creyeron estúpidamente que la epidemia no llegaría a Suecia en absoluto"17. Por otro lado, el mismo primer ministro Stefan Löfven, tuvo que reconocer en la primera semana de mayo que: "La preparación no fue lo suficientemente buena"18. No obstante, el día 7 de mayo, el país ya había superado las 3.000 muertes. A pesar de la perplejidad de estas medidas, el gobierno ha mantenido las recomendaciones del Organismo de Salud Pública del país. En esta paradójica situación, 21 científicos e investigadores publicaron una columna exigiendo "medidas rápidas y radicales", incluyendo el cierre de escuelas y restaurantes ${ }^{19}$. El debate se ha iniciado entre el gobierno y las autoridades sanitarias que han seguido presionando para que se adopte una estrategia a largo plazo, remarcando que la contención sólo funciona durante períodos cortos. Critican contundentemente a la Agencia de Salud Pública y advierten que Suecia sigue una curva de enfermos similar a la de Italia, y exigen que el poder político actúe en consecuencia.

Entre el 7 al 9 de abril, murieron en Suecia 10,2 personas por millón de habitantes al día, por covid-19. Esta cifra superaba a la de otros países europeos: en Italia la cifra fue de

\footnotetext{
${ }^{16}$ Government Office of Sweden.

17 Euronews, Rafael Cereceda. ¿El modelo sueco frente al coronavirus empieza a hacer aguas ante el aumento de fallecidos?, 6 de mayo de 2020. Disponible en: https://es.euronews.com/2020/04/16/el-modelo-sueco-frente-al-coronavirus-empieza-a-hacer-aguasante-el-aumento-de-fallecidos

18 lbid.

19 Diario Dagens Nyheter.
} 
9,7; en Dinamarca fue de 2,9; en Noruega 2,0; y en Finlandia 0,9, respectivamente ${ }^{20}$. De estas cifras es posible deducir que en Suecia han muerto más de diez veces más personas a causa del coronavirus que en Finlandia. En Finlandia todos los cafés y restaurantes están cerrados, al igual que las escuelas están cerradas, y las reuniones de más de diez personas están prohibidas. Por otro lado, Noruega, con muertes por millón de habitantes cinco veces más bajas que Suecia, no ha tenido reglamentaciones de conducta tan estrictas como Finlandia, pero de todas formas mucho más estrictas que la de Suecia. Para Camilla Stoltenberg, directora del Instituto Noruego de Salud Pública:

Noruega ha sido absolutamente crucial tener más control en esta fase, el implementar numerosas medidas en una etapa temprana (...) Ha sido importante para ganar tiempo y prepararse para lo que esté por venir y tener buenas condiciones para enfrentar la epidemia en el futuro $^{21}$ (STOLTENBERG, 2020).

Tegnell, de manera similar a Johan Giesecke, poseen una post formación en la London School de Higiene y Medicina Tropical, en cuyos departamentos se inspiró la política adoptada en un principio por Boris Johnson, a saber, la mitigación de la epidemia para evitar el desbordamiento de los hospitales, mientras se expande entre la población hasta que alcanza inmunidad grupal o "inmunidad de rebaño"22. Giesecke no aprobó el cambio de actitud del gobierno británico ${ }^{23}$, al defender los efectos negativos para la salud y para la sociedad debido a las medidas autoritarias y restrictivas tomadas por los gobiernos, con el argumento de que el confinamiento no soluciona el problema. Por otro lado, considera que la cifra final de fallecidos en cada país al final será similar, puesto que el virus se expandirá hasta que la mayoría de la población desarrolle inmunidad, o en unos meses, que sea posible disponer de una vacuna. Mark Handley, profesor de Sistemas en red en University College London, ha publicado unas series de gráficos que exponen la evolución de la pandemia en los países nórdicos y el aumento de infecciones por millón de habitantes y confirma la hipótesis de que en Suecia el descenso de las infecciones se produjo de forma

${ }^{20}$ Worldometer. Disponible en: https://www.worldometers.info/coronavirus/

${ }^{21}$ Aktuellt, Norska folkhälsodirektören: "För tidigt säga att vi lyckats" 9 april, 2020. Disponible en: https://www.svt.se/nyheter/utrikes/norska-folkhalsodirektoren-for-tidigt-saga-att-man-lyckats

22 The Conversation, ¿Qué es la inmunidad de rebaño y por qué Reino Unido confía en ella frente al coronavirus?, 20 march, 2020. Disponible en:

https://theconversation.com/que-es-la-inmunidad-de-rebano-y-por-que-reino-unido-confia-en-ellafrente-al-coronavirus-134175

${ }^{23}$ Entrevista en Unherd. Which epidemiologist do you believe? The debate about lockdown is not a contest between good and evil, 27 abril 2020. Disponible en: https://unherd.com/2020/04/whichepidemiologist-do-you-believe/ 
similar a otros países con el confinamiento ${ }^{24}$.

En este contexto, ¿El modelo sueco ha aportado alguna ventaja? ¿Es todavía temprano para evaluarlo? Como todo el proceso que envuelve el covid-19 todavía no se dispone de suficientes informaciones comparadas empíricamente. Suecia se ha fundamentado en dos pilares: autodisciplina y estructura de trabajo. La ministra de asuntos exteriores, Ann Linde, ha confiado en la responsabilidad cívica de sus ciudadanos para prevenir la propagación del virus. Sin embargo, esta responsabilidad no se encuentra sólo en la cultura y la forma de vida de la población, sino que el gobierno en sus acciones ha dado ejemplo a toda la sociedad. En el ámbito empresarial, se ha confiado en las empresas y los trabajadores para que asuman su responsabilidad. A partir de estas constataciones diversos gobiernos se han preguntado sobre la posibilidad de implementar el modelo en sus respectivos países. Goldman Sachs, ha declarado expresamente: "la experiencia sueca no se puede extrapolar" 25 , por causa de las características culturales específicas de este país. Las medidas del Gobierno han reflejado la tradición sueca democrática y las estructuras de la sociedad, en las que el Gobierno no tiene la potestad para decretar toque de queda, a no ser que estalle una guerra.

Para el Anders Tegnell ${ }^{26}$ (epidemiólogo y jefe de la Agencia de Salud Pública de Suecia) el objetivo principal ha sido mantener las tasas de transmisión en un nivel tal que el sistema de salud no colapse. Para este epidemiólogo no es posible seguir manteniendo una estrategia de aislamiento social (cierre de fronteras y establecimientos públicos) ya que ni es sostenible ni viable en el tiempo. Considera que la "inmunidad colectiva" permite afrontar esta pandemia en el largo plazo, aunque esta inmunidad no es el foco de su estrategia, sino una condición que puede derivarse a partir de ella. Sin embargo, diversos estudios han constatado que la inmunidad colectiva como una condición, se logra cuando menos el 70\% de la población, se vuelve inmune a la enfermedad, ya sea por recuperación o mediante la vacuna. Esta situación genera que en el corto plazo las muertes sean mayores que en relación a otros países, aunque hace menos probable la propagación del virus dado que no hay suficientes portadores infecciosos para contagiar.

En suma, es difícil valorar la efectividad de la estrategia del gobierno, que en el día 15 de mayo contabilizó 29.677 casos confirmados, 4.971 recuperados y 3.674

24 Leonoticias. Suecia envidia el rigor de sus vecinos, 25 de abril 2020. Disponible en: https://www.leonoticias.com/internacional/union-europea/envidia-sueca-rigor-20200424183308ntrc.html?ref=https\%3A\%2F\%2Fwww.google.com.br\%2F

$25 \mathrm{lbid}$.

${ }^{26}$ La Tercera. Anders Tegnell, el epidemiólogo detrás de la polémica estrategia de Suecia contra el coronavirus, 13 de abril de 2020. Disponible en: https://www.latercera.com/la-tercera-pm/noticia/anders-tegnell-elepidemiologo-detras-de-la-polemica-estrategia-de-suecia-contra-el-coronavirus/wdyjfuk4pzgafiq5vc7ocluyr4/ 
fallecimientos. En el mes de abril, el FMI publicó que Suecia sufriría una contracción anual estimada del PIB -6.5\% (mientras que en la zona euro la caída sería de un -7.5 por ciento) y una ligera contracción del $0.3 \%$ del primer trimestre ${ }^{27}$. A mediados de mayo, la ministra de economía, Magdalena Andersson, ya se refería a una caída del $10 \%$ del PIB ${ }^{28}$.

\subsection{Alemania}

Alemania, se ha mostrado como la nación más efectiva, por ser el país europeo con una gran población y con menos fallecimientos. En este país el sistema científico, el político y el económico han logrado un cierto equilibrio. El hecho que el sistema de salud no haya colapsado fue debido a la preparación y efectividad de este sistema. Desde los inicios de los casos, el gobierno mantuvo una estrategia clave ante la "urgencia" del problema al poner en marcha una campaña masiva de pruebas entre la población. Con ello fue posible establecer una red pública, mutualista y privada de laboratorios con el objetivo de lograr el control de la pandemia. Alemania ha partido de un modelo de sistema sanitario que ha evidenciado la fortaleza y eficiencia de su sistema de salud y ha combinado importantes recursos e inversiones previas a una gestión eficaz. El modelo de colaboración público-privada e institucional que ha sido un factor que impulsó el alcance de la eficiencia con el mejor resultado al menor coste posible. Por otro lado, la agilidad de la gestión ha caracterizado a los elementos del sistema sanitario (centros de salud, clínicas especializadas, laboratorios y grandes hospitales), que ha funcionado de forma óptima. Alrededor del $70 \%$ de los centros sanitarios de Alemania están gestionados por compañías privadas, fundaciones, organizaciones mutuales benéficas o grupos religiosos, siendo que el $30 \%$ restante tiene una gestión pública directa. Esta estructura incorpora un alto grado de elementos de gestión empresarial al manejo de los centros sanitarios, con lo que se combinan un pensamiento de flexibilidad para adaptarse a las circunstancias. Como consecuencia los hospitales del país disponen de más facilidad para utilizar economías de escala en el uso de sus recursos y más capacidad de negociación con proveedores, liberándose de las trabas burocráticas y optimizando costes en las compras de material.

Sin embargo, pese a su potente estado social (y sistema sanitario) han aparecido problemas con la pandemia relativos a la transferencia de responsabilidades y coordinación ${ }^{29}$ en el ámbito de la salud entre los Länder y los municipios. La pandemia

${ }^{27}$ La vanguardia, La arriesgada normalidad sueca, 31 marzo 2010.

${ }^{28}$ El país, 21 mayo 2020.

${ }^{29}$ Deutschlandfunk Kultur. Forderung nach mehr Kompetenzen für den Bund, 12 de marzo de 2020. En: https://www.deutschlandfunkkultur.de/corona-pandemie-forderung-nach-mehr-kompetenzen-fuer- 
comenzó en Alemania el 27 de enero del 2020 con la identificación del primer caso en Múnich. En las primeras semanas la mayoría de los casos fueron identificados en una fábrica de componentes de automóvil. A partir del 26 de febrero ya se registran casos en Baden-Württemberg y otros por viajes procedentes de Italia, China e Irán. El centro de epidemiología y control de enfermedades es asesorado por el Instituto Robert Koch (RKI) y juntos gestionaron el plan nacional de pandemias. En la primera fase, los casos fueron gestionados en el "estadio de contención" con el objetivo de minimizar su expansión. En 11 de marzo, la canciller Angela Merkel afirmó que el país estaba bien preparado y que inicialmente las medidas de cuarentena y distanciamiento social no serían necesarias ${ }^{30}$. Ante el aumento rápido de contagiados de caso el 13 de marzo pasó al nivel "de protección" en el que fueron cerradas escuelas, universidades, jardines de infancia y residencia para personas mayores. El 22 de marzo se anunció un toque nacional de cuarentena. Desde un principio el coordinador de Emergencias Infecciosas del Instituto de Virología del Charité en Berlín Christian Drosten apostó por la aplicación masiva de pruebas entre la población, focalizando los núcleos de infección con el objetivo de identificar los contactos y de esta forma controlar la expansión de la pandemia ${ }^{31}$. Al bajo número de fallecidos corresponde también un sistema hospitalario y un sistema de unidades de cuidados intensivos muy extenso y superior al de otros países europeos.

\subsection{España}

En España la opinión mayoritaria es que se ha reaccionado demasiado tarde ${ }^{32}$, ya que la recomendación de permanecer en casa tuvo lugar cuando ya había más de 1.000 contagios en Madrid $^{33}$. El 7 de febrero de 2020, el Foro Económico Mundial otorgaba a España el título de mejor sanidad del mundo, siendo además el tercer país en esperanza de vida $^{34}$.

La OMS declaró que el brote de virus era una pandemia el 11 de marzo. Tres días

\footnotetext{
den.1008.de.html?dram:article_id $=472312$

30 Declaraciones recogidas en: EURACTIV.de

${ }^{31}$ Der Tagesspiegel. Neue statistiche Auswertung bestätig alten Verdacht, 03 de junio de 2020. En: https://www.tagesspiegel.de/wissen/drosten-studie-ueberarbeitet-neue-statistische-auswertungbestaetigt-alten-verdacht/25882680.html

${ }^{32}$ Financial Times, 2 marzo 2020, Political divisions depeen Spain battles coronavirus.

${ }^{33}$ El Pais, Espanha e Coreia do Sul, exemplos opostos de controle epidemiológico do coronavírus, 16 marzo 2020. Disponible en: https://brasil.elpais.com/sociedade/2020-03-16/coreia-e-espanhaexemplos-opostos-de-controle-epidemiologico-do-coronavirus.html

34 Redacción Médica. El foro Económico Mundial da a España el título de mejor sanidad del mundo, 7 febrero 2020. Disponible en: https://www.redaccionmedica.com/secciones/sanidad-hoy/espanacuenta-con-la-mejor-sanidad-el-mundo-segun-el-foro-economico-mundial-8476. Consultado el 7 de febrero de 2020.
} 
más tarde ya se producían una fuerte extensión de los contagios en las ciudades de Madrid, Barcelona y otros puntos del país. El Consejo de Ministros declaraba el estado de alarma. Antes la convocatoria de la manifestación multitudinaria prevista para el Día Internacional de la Mujer para el 8 de marzo, a pesar de ello, el director del Centro de Coordinación de Alertas y Emergencias Sanitarias Fernando Simón mantuvo una posición ambigua cuando fue preguntado sobre esta manifestación: "Si mi hijo me pregunta si puede ir le diré que haga lo que él quiera", y que no recomendaba a "nada a nadie ", y aseguró que cada persona debía considerar asistir o no a las manifestaciones feministas en Madrid. ${ }^{35}$

No nos detendremos aquí a analizar los problemas heredados de las administraciones públicas, ya abordadas por diversos estudios crónicos (Jiménez Asensio, 2020; Ramio 2015) en los que se identifican sus problemas estructurales ("visión cortoplacista de la política", "marco normativo obsoleto", envejecimiento de las plantillas, etc.).

Durante la pandemia, ya fueron puestos a prueba mecanismos y técnicas de comunicación información (TICs) y prestación de servicios de la administración y gestión pública, algunos ya existentes y utilizados (administracion.gob.es), otros infrautilizados (videoconferencias) y otros novedosos (Asistente Virtual de la Seguridad Social, sites de municipios). La pandemia ha obligado a agilizar en carácter de urgencia las formas de trabajo de las administraciones y adaptarlas a unas circunstancias excepcionales. Su organización se ha tenido que extender medidas incipientes antes de la pandemia (flexibilización, reorganización de turnos, teletrabajo, homework).

\section{Modelos de gestión}

El modelo de previsión de Alemania hizo que el país obtuviera la capacidad logística de realizar, ya en el 20 de marzo, 160.000 exámenes diagnósticos por semana, mientras que Italia, Gran Bretaña y España sólo habían podido realizar 150.000, 50.000 y 30.000 exámenes diagnósticos, respectivamente. Esta estrategia de diagnósticos ( pruebas rápidas focalizadas) incide en estos países muchas en personas con el virus que no fueron diagnosticados por tener síntomas o por la falta de material del examen para la detección de la enfermedad con lo que la pandemia se extendió de manera descontrolada. En Alemania convergieron de manera más aproximada el número de casos detectados, respecto al número de infectados ${ }^{36}$.

\footnotetext{
${ }^{35}$ Declaraciones en La Vanguardia, 7 marzo 2020.

${ }^{36}$ BBC News. Alejandro Millán Valencia. ¿Por qué Alemania tiene un número tan bajo de muertos por covid-19 en comparación con otros países?, 21 marzo 2020. Disponible en:

https://www.bbc.com/mundo/noticias-internacional-51980118
} 
Algo diferente ha pasado en España en que en ningún momento se ha dispuesto de estimaciones creíbles acerca de la expansión de la pandemia, con muy pocas pruebas de detección. El resultado ha sido una política a ciegas y muy lenta hacia la normalización. Si bien la libertad operativa para comprar equipos médicos ha sido "excepcional", el resultado fue "extremadamente ineficiente"37. En España, el Sistema Nacional de Salud tiene como modelo el concurso, el cual comporta varios problemas. Por un lado, no tiene capacidad de gestión de la contratación directa, por otro, inunda la contratación de opacidades y costes periféricos. Ese modelo de operaciones de compra, que va más allá de convocar concursos de suministro, es el habitual en los centros sanitarios alemanes, con lo que disponen de la capacidad de conocer "perfectamente" los mercados exportadores de productos sanitarios. En esta perspectiva de gestión privada, se ha actuado en un "medio habitual y lo han hecho no solo con eficacia y eficiencia, sino también con transparencia". El informe también considera que la organización de los centros sanitarios alemanes sigue los criterios y los modelos de la gestión corporativa: "sin ataduras estatutarias contrarias a los valores de eficacia y transparencia", y cree que eso facilita la reorganización de los servicios o la disponibilidad de persona ${ }^{38}$.

En suma, en Alemania el sistema de sanidad evolucionó de un modelo de gestión sanitario amenazado por la falta de inversiones y de recursos públicos durante las dos últimas décadas (en especial desde la Gran Crisis del año 2008) hacia un modelo de previsión, financiado mediante el complemento de seguros públicos y privados con el objetivo de asegurar que sea sostenible a largo plazo. En España todavía se está lejos de lograr este tipo de cooperación, salvo alguna comunidad autónoma como es el caso de Cataluña. Para poder asumir con éxito una estrategia similar a la de Alemania es necesaria una "una infraestructura que la sostenga", siendo que Alemania ha dispuesto de este sistema sanitario "vital para controlar esta pandemia y permitir la subsistencia de la economía y de un modelo de sociedad libremente elegido"39. No obstante, aparece aquí una paradoja en la afirmación que en España esa "eficacia" de coordinación y cooperación entre lo público y lo privado "solo" ha tenido lugar en la Comunidad de Madrid, puesto que la Comunidad se "ha dotado de sólidas infraestructuras y un modelo de gestión flexible que,

\footnotetext{
${ }^{37}$ Instituto Coordenadas, 2 mayo 2020.

${ }^{38}$ Libre mercado. Instituto Coordenadas atribuye el "éxito" en la gestión de Alemania a la "eficiencia de su sistema sanitario, 5 abril 2020. Disponible en: https://www.libremercado.com/2020-0504/coronavirus-instituto-coordenadas-atribuye-la-gestion-de-alemania-a-su-sistema-sanitario$1276657011 /$

${ }^{39}$ Declaraciones del vicepresidente ejecutivo del Instituto Coordenadas. De gobernanza y economía aplicada, Jesús Sánchez. Disponible en: https://www.institutocoordenadas.com/es/analisis/estrategiaalemania-gestion-covid-19-sistema-sanitario-eficiencia_20063_102.html
} 
con todo y a pesar de todo, ha dispuesto de un sistema de salud que ha hecho frente a una de las más devastadoras situaciones imaginables" ${ }^{40}$. Sin embargo, no ha tenido en cuenta que en la Comunidad de Madrid es donde se han producido más casos (66.005) y fallecimientos (8.809), muy por encima de Cataluña (con 55.464 casos y 5.882 fallecidos), o el País Vasco (con 13.257 casos y 1.454 fallecidos), lugares con sistema de cooperación público-privada muy avanzados (Tabla 1).

La prensa alemana se ha hecho eco de la dramática situación en España ${ }^{41}$ : aparentemente, se han producido fallos muy graves, y no desde hace poco tiempo. Alguien será responsable de estos errores que han tenido muchas muertes como consecuencia. $Y$ seguramente no será el personal de cuidados, sobrepasado de trabajo, motivo por el que viene quejándose desde hace tiempo (FRANKENBERGER, 2020).

En muchas de ellas el ejército descubrió cadáveres de fallecidos desde hacía algunos días. El gobierno español intervino inmediatamente en las residencias de ancianos poniéndolas bajo control especial con la aprobación de medidas drásticas. Sin embargo, será necesario formular la pregunta a quienes han sido los responsables de la gestión: ¿Cómo pudo ocurrir algo así?

\footnotetext{
${ }^{40}$ Ibid.
}

${ }^{41}$ Klaus-Dieter Frankenberger, Frankfurter Rundschau, 22 de abril de 2020. Frankfurter Allgemeniner Zeitung, 25 abril 2020. "Tödliche Missstände im System". 
Tabla 1 - Estrategia de los gobiernos y éxito en la lucha contra la pandemia (17 mayo - 15 junio 2020)

\begin{tabular}{|c|c|c|c|c|c|}
\hline & $\begin{array}{l}\text { Estrategia } \\
\text { del gobierno }\end{array}$ & $\begin{array}{l}\text { Casos por } \\
1.000 .000 \\
\text { Habitantes } \\
(2)(4)\end{array}$ & $\begin{array}{l}\text { Muertes } \\
\text { por } \\
1.000 .000 \\
\text { habitantes } \\
(2) \\
\end{array}$ & $\begin{array}{l}\text { Test } \\
\text { realizados } \\
\times 1.000 \\
\text { habitantes (1) } \\
\text { totales }(2)\end{array}$ & $\begin{array}{l}\text { Número total } \\
\text { de casos } \\
\text { confirmados } \\
17 \text { mayo (2) } \\
15 \text { junio (3) }\end{array}$ \\
\hline Suecia & $\begin{array}{l}\text { Restricciones } \\
\text { voluntarias }\end{array}$ & $\begin{array}{r}2.546(2) \\
5.110 .67(4) \\
\end{array}$ & 312 & $\begin{array}{r}32.18(1) \\
177.500(2) \\
\end{array}$ & $\begin{array}{l}30.143(2) \\
37.542(3) \\
\end{array}$ \\
\hline Noruega & $\begin{array}{l}\text { Confinamient } \\
\text { o total }\end{array}$ & $\begin{array}{r}1.509(2) \\
1.587 .46(4)\end{array}$ & 41 & $\begin{array}{r}51.14(1) \\
216.350(2)\end{array}$ & $\begin{array}{l}8.244(2) \\
8.411(3)\end{array}$ \\
\hline Dinamarca & $\begin{array}{l}\text { Confinamient } \\
\text { o total }\end{array}$ & $\begin{array}{r}1.791(2) \\
2.105 .07(4)\end{array}$ & 91 & $\begin{array}{r}130.28(1) \\
455.613(2)\end{array}$ & $\begin{array}{l}10.927(2) \\
11.699(3)\end{array}$ \\
\hline Alemania & $\begin{array}{l}\text { Confinamient } \\
\text { o parcial }\end{array}$ & $\begin{array}{r}2.063(2) \\
2.225 .5(4) \\
\end{array}$ & 91 & $\begin{array}{r}56.03(1) \\
3.147 .771(2) \\
\end{array}$ & $\begin{array}{r}176.450(2) \\
179.364(3) \\
\end{array}$ \\
\hline España & $\begin{array}{l}\text { Confinamient } \\
\text { o total }\end{array}$ & $\begin{array}{r}4.764(2) \\
5.217 .18(4)\end{array}$ & 565 & $\begin{array}{r}60.38(1) \\
3.037 .840(2)\end{array}$ & $\begin{array}{r}277.719(2) \\
239.932(3) \\
25 \text { mayo } \\
\text { cambio de } \\
\text { metodología } \\
\end{array}$ \\
\hline Italia & $\begin{array}{l}\text { Confinamient } \\
\text { o total }\end{array}$ & $\begin{array}{r}3.623(2) \\
3.919 .65(4) \\
\end{array}$ & 505 & $\begin{array}{r}46.58(1) \\
2.944 .859(2) \\
\end{array}$ & $\begin{array}{l}224.760(2) \\
232.248(3)\end{array}$ \\
\hline
\end{tabular}

Fuentes:

(2) https://www.worldometers.info/coronavirus/\#countries.

Coronavirus COVID-19 Global Cases by the Center for Systems Science and Engineering (CSSE) at Johns Hopkins University (JHU).

ArcGIS. Johns Hopkins CSSE, fecha: 17 de mayo de 2020.

European Centre for Disease Prevention and Control (ECDC)

(1) Our World in Data, Oxford, fecha: 13 de junio de 2020, https://ourworldindata.org/grapher/totalconfirmed-deaths-of-covid-19-per-million-people-vs-gdp-per-

capita?xScale=linear\&country=DNK DEU NOR

(3) Our world in data, Oxford, fecha: 15 de junio de 2020 https://ourworldindata.org/grapher/totalcases-covid-19?country=owid_wrl dnk deu ita nor esp swe

(4) Our world in data, Oxford, fecha: 15 de junio de 2020 https://ourworldindata.org/grapher/totalconfirmed-cases-of-covid-19-per-million-people?region=Europe

\subsection{Administración pública y reconfiguración sociedad-Estado}

La mayoría de las predicciones y prospecciones realizadas en los últimos años sobre la Administración pública, la extensión y las responsabilidades del Estado, han quedado en su mayoría obsoletas, mientras que otras se verán reforzadas por la rapidez e impactos de los acontecimientos, ganando en actualidad. La reconfiguración del vínculo sociedadEstado, comprende diversos niveles y ámbitos de análisis: política y formas de gobierno, sociedad, gestión, administración pública, seguridad, etc. Los postulados de la Nueva Gestión Pública han correspondido a un delineamiento de la relación administración-Estado, siendo el impulso para la renovación de las administraciones públicas durante el último cuarto de siglo. El escenario post virus es, en algunos aspectos, todavía inseguro, al configurarse dos modelos contrapuestos. 


\subsection{Escenario post virus: modelos autoexcluyentes}

Expertos coinciden en que el escenario post virus abre inseguridades y contingencias y, por lo tanto, nuevas posibilidades. Es evidente que habrá que explorar los posibles cambios del Estado y de la administración pública desde la perspectiva de la hipercomplejidad que caracteriza las sociedades modernas. Complejidad en el sentido sistémico significa contingencia, y contingencia significa riesgo y peligro. Viene a ser que algo no es ni imposible ni necesario pero que puede ser. Esta doble negación se presta a ambigüedades y por lo tanto a interpretaciones diversas. Para la idea que presentamos en este texto, posee el valor de que cualquier propuesta de cambio es posible y, por lo tanto, podría ser efectiva. La cuestión para nosotros es: ¿En qué dirección se producirá este cambio? Aquí aparece el gran desafío para las democracias liberales, el Estado y la administración pública.

Es posible identificar dos modelos: 1) Estado reducido y continuidad económica; 2) Estado extenso, vinculado con la presentación de un Estado-céntrico. Los dos modelos ya son objeto de identificación en diversos países, y seguirán en ampliación en el futuro próximo. No obstante, en la perspectiva de la complejidad, aparecen paradojas en los dos modelos. La autonomía del sistema administrativo respecto a la política puede suponer dos fenómenos diferentes. Por un lado, no estar sometido al control interesado del sistema político, y por lo tanto favorecer su función elemental de administrar. Por otro, puede adquirir una preponderancia respecto al sistema político por lo que puede quedarse sin ningún tipo de control político.

Con la gobernanza de la pandemia se han evidenciado los modelos de gestión de la sociedad, las funciones del Estado, sus paradojas, y en consecuencia el perfilamiento y profundización de las tendencias ya iniciadas y en curso, referentes al vínculo sociedadEstado y al futuro modelo de Estado. Ha sido repetido que la intención por parte de los gobiernos de confinamiento de la población (horizontal, vertical, "inmunidad del rebaño" etc.), obedece a la lógica de evitar el colapso del sistema de salud de cada país. Cada uno de estos sistemas nacionales tiene una capacidad máxima de atención de los infectados por la pandemia y una cantidad limitada de camas con respiradores automáticos y el personal médico especializado para su manejo. Para evitar el colapso, o sea, la posibilidad de no poder atender a todos los casos necesarios en una fecha clave, es necesario que el número de contaminados no sobrepase en ningún momento un máximo que el sistema sanitario pueda gestionar y atender, por lo que ha sido necesario que la curva de pacientes 
necesitados de atención médica se mantenga lo más plana posible, durante el espacio de tiempo más extenso, en lugar de una curva de rápida ascensión y durante poco tiempo, hasta alcanzarse el pico de los casos atendidos. Por otro lado, también ha proporcionado al sistema científico más tiempo para el desarrollo de un tratamiento o del desarrollo de una vacuna.

El confinamiento vertical ha correspondido a la lógica de evitarse al máximo la paralización económica de los países afectados, con el argumento de que, en el ámbito económico, los impactos de la pandemia serán peores, por destruirse la base de la riqueza y el número de empleos en el país. Este tipo de confinamiento está direccionado a la población de riesgo (más de 60 años y/o con enfermedades crónicas). En la fase inicial de la pandemia esta medida fue recomendada por Gran Bretaña, Norteamérica y Brasil. Por otro lado, el confinamiento horizontal implica la mayor parte de la población. Puede tratarse de un confinamiento irregular, cuando para ser efectivo se recomienda un $70 \%$ de la población (según recomendación de la OMS) y debe ir acompañado de una prueba preventiva, focalizando los puntos catalizadores y las personas en los que se inició la pandemia. Fue utilizado masivamente en Alemania y se ha mostrado como el más efectivo, al ser el país europeo con menos fallecimientos. ¿A qué lógicas político-administrativas y de entendimiento del estado corresponde cada modelo? Hemos realizado un esbozo de delineamiento que corresponde a dos lógicas: Estado reducido y Estado extensivo (en su presentación sistémica Estado-céntrico). Ambos modelos no están libres de paradojas (VIDAL, 2019).

\subsection{Estado reducido jerárquico}

La propuesta de reducir el tamaño y reformular las funciones del Estado no es nueva, manifestándose en el plano político recientemente en un contexto de crisis de la democracia liberal, la emergencia de partidos y movimientos populistas radicales, y la sustitución por regímenes alocráticos. Puede adquirir dos formas diferentes: una organización del Estado centralizador y una organización policéntrica. En el contexto de crisis económica (impactos de la Gran Recesión del año 2008), se pretende reducir niveles decisorios en el plano multinivel, eliminando estructuras que puedan molestar la toma de decisiones rápidas. Desde hace unos años ya se viene implementando en Norteamérica, con la priorización de la responsabilidad individual en todos los ámbitos (educación, sanidad, empleo, jubilación etc.), lo que significa que en situaciones de riesgo y peligro social el Estado no será responsable. El sistema económico debe ser dejado a la iniciativa privada con la mínima intervención del Estado. La gestión de la pandemia de coronavirus ha mostrado la contingencia de este modelo. Se podría haber declarado el confinamiento vertical si hubiera 
existido un sistema sanitario con capacidad para atender a toda la población con calidad para una situación excepcional como es en esta pandemia. El asumir un confinamiento vertical viene a significar que el país debería disponer de un sistema de salud exponencialmente más extenso y amplio para la población (en principio, pero sin exclusión para situaciones de emergencia como la actual) en los niveles cuantitativo y cualitativo. Pero con esta pandemia también han emergido sus paradojas al reivindicar movimientos ciudadanos sobre la libertad civil (a menudo en gobiernos de extrema derecha) frente a los métodos de control, vigilancia y confinamiento impuestos.

\subsection{Estado extensivo (Estado-céntrico)}

La pandemia ha servido también para que diversas publicaciones puedan predecir el esperado colapso del sistema de libre mercado o capitalista. Sus propuestas abarcan desde visiones apocalípticas del futuro (exclusivamente imaginativas) con hasta predicciones realistas. Para sectores políticos autodenominados de izquierda, el confinamiento ha poseído una virtud y predicción: con la ampliación temporal de la crisis del coronavirus, también cambiará enormemente el orden económico tal y como lo hemos conocido. La perspectiva es que la economía de mercado tal como se conoce probablemente se abolirá parcialmente, en la que la propiedad privada y la competencia serán menos importantes, y la influencia del Estado aumentará masivamente. Se retoma así la teoría Estado-céntrica, en la que el Estado es el principal productor de bienestar social, que también puede significar paradójicamente mayor control burocrático y centralización administrativa.

En ambos modelos aparecen también paradojas, puesto que un Estado reducido puede favorecer formas de gobierno como autogobierno, autoorganización, autorregulación, o glocalización, mientras que un estado extenso tendería a la absorción de iniciativas de este tipo, en pro de políticas estatales centralizadas y homogeneizadoras en un contexto económico globalizador. Esta disyuntiva aparecería en estados de orden federal o descentralizados.

\section{Unas reflexiones provisionales}

Las administraciones públicas, como un sistema autónomo, se verán afectadas por los cambios procedentes de su entorno, acelerados de manera rápida por la pandemia del covid-19. Muchas de las posibilidades que se han puesto en marcha ya estaban presentes, aunque de forma incipiente en la administración (teletrabajo, homework, flexibilización de horarios, etc.). Estas posibilidades serán habituales en las organizaciones y en la 
administración pública de los próximos años. Con la crisis del covid-19, los fallos digitales de la administración y gestión pública se han vuelto más claras y con consecuencias dolorosas. Las posibles soluciones propuestas tienen brechas de seguridad importantes y faltan los requisitos elementales para la identificación electrónica.

La administración pública tendrá que dejar su aparente área de confort (jurídico y económico) para entrar definitivamente en la contingencia. Esto significará un amplio abanico de posibilidades, aunque no necesarios, exigirán de los funcionarios, de la estructura y de sus funciones una constante adaptación a las comunicaciones (en forma ya no solo de demandas sino en maneras de coproducción de servicios) procedentes de la política (y del modelo de gobernanza) del estado y de la sociedad. El riesgo será constante con los intentos de "colonización" de la política que pueden dirigirse hacia una orientación progresista o conservadora. Esta colonización ha sido denunciada frecuentemente, aunque con pocos resultados prácticos como se ha hecho evidente durante la pandemia. Esta situación se ha producido por los cuatro vicios de los sistemas políticos: meritocracia política (será necesario repensar problemas estructurales que han lastrado la administración pública); partitocrazia (control de los partidos de los puestos públicos); lotizzazione (reparto de cuotas); y tangentopoli (polis de los sobornos) extensible en particular en los países mediterráneos (España, y sus Comunidades Autónomas, e Italia) ${ }^{42}$. Estos vicios no han sido inhabituales en España y en las Comunidades Autónomas, en las que ministros o secretarios responsables de las residencias de ancianos o del área de salud poseían formación o experiencia en áreas no afines a la salud (formación en educadores/as psicopedagógicos/as, maestro/as, filósofos/as o licenciados/as en ciencias físicas), entre otras formaciones ajenas a su responsabilidad. Los impactos han sido manifiestos.

La administración asume los límites y prioridades de la política. La administración deberá mantener su autonomía basada en criterios técnicos (y meritocráticos) en todos sus niveles, en especial en los superiores de dirección. En el delineamiento de la relación administración pública y Estado, el sistema político dependerá de varios factores: el modelo de gobernanza, la fuerza política en el poder, la necesaria revolución político-técnica, los modelos y prácticas de audiencias públicas que se apliquen, el tipo de cooperación públicoprivada, y, en definitiva, la capacidad de autonomía (y auto referencialidad) de la administración pública frente al colonialismo de la política, sin criterios técnicos.

En el plano político ya se ha dado el inicio de una sucesión de dimisiones, renuncias

42 Instituto di Reserce Sulla Publica Administrazione, 2014. 
y retiros de responsables políticos e institucionales en prácticamente todos los países afectados. Elecciones generales legislativas planeadas para los años 2021 y 2022, medirán la confianza que la ciudadanía ha depositado en sus respectivos gobiernos durante la gestión de la pandemia, y pasarán factura a la forma en que se repartió el financiamiento del pago de los gastos de la emergencia sanitaria, en las ayudas y políticas públicas de emergencia implementadas.

En el contexto de la post pandemia y ante la grave crisis económica, laboral ${ }^{43}$ y social que están viviendo los países y en el contexto de la reformulación de las responsabilidades y extensión del Estado, se perfilan y presentan diferentes desafíos para la administración pública en el futuro. Es posible perfilar dos modelos principales:

Primero, en un contexto de transformación de las responsabilidades del Estado - ya iniciado unos años antes - y de su relación con la sociedad, significa que según el modelo de actuación del Estado que se imponga, que varía entre un Estado más amplio u otro más reducido, aunque ambos vinculados con procesos de re-descentralización, la administración y gestión pública se verá afectada en su autonomía, capacidad y ámbito de acción, y en sus formas tradicionales de planificar el trabajo.

Segundo, según el modelo de Estado que se imponga, también se abrirán posibilidades de introducir, o de acelerar cambios estructurales y la generalización de las posibilidades de las tecnologías de información y comunicación ya iniciadas unos años antes, (e-government, e-administration, e-democracy) y en las que se resaltan los aspectos positivos. Ello puede conducir a nuevas formas de "gobernanza inteligente", "gobierno electrónico", pero también pueden representar la implementación de nuevas posibilidades de vigilancia y control, siendo vistas con desconfianza (ATTOUR; CHAUPAIN-GUILLOT, 2020).

Cada una de estas tendencias presentadas aquí de forma esquemática corresponde a diferentes presupuestos conceptuales, políticos y de gobernanza sobre la manera de entender la regulación de la sociedad en su totalidad. La Nueva Gobernanza Pública ha reemplazado gradualmente a las organizaciones de servicios dispersos (asociaciones, fundaciones, Tercer sector, cooperativas de servicios) por un entramado de redes de sistemas de prestación de servicios públicos, cuyo funcionamiento se basa en la interacción de una multiplicidad de actores para lograr los objetivos sociales y la prestación de servicios públicos con énfasis en la asociación y la colaboración. Se trata de una adaptación del

${ }^{43}$ El País, Economía, 5 de mayo de 2020. 
modelo institucional jerárquico (top down) tradicional, hacia un modelo de inspiración compleja para permitir abordar las necesidades sociales y también como instrumento para la inclusión social. La coproducción de servicios adquiere una nueva dimensión y adquiere una importancia central de la producción de servicios públicos.

En los países de la Unión Europea ya se identifica un vertiginoso aumento de la pobreza, similar (o incluso superior) a la existente en el año 2008, debido al desempleo masivo que ha causado la pandemia, y a la falta de ahorro de muchas familias. Se discute la introducción definitiva del Ingreso Mínimo Vital o Renta Básica Universal, aunque sin consenso en el ámbito político. También se vislumbra un futuro de demandas judiciales impuestas por la ciudadanía contra la equivocada gestión de los gobiernos y de las residencias de ancianos y centros de tercera edad. Los problemas y fenómenos han sido identificados transversalmente en los países de la UE:

1) La hipótesis sobre la falta de centralización nacional del sistema de salud ha sido un factor de mayor propagación nacional de la enfermedad (Suecia). Este problema se ha detectado en especial en los países de organización descentralizada, como España en que el Ministerio de Sanidad se encontró, al inicio de la pandemia, con sus competencias totalmente vacías en favor de las Comunidades autónomas, hecho que dificultó la compra de material sanitario en el extranjero.

2) La gestión de las instituciones para ancianos. En la mayoría de los países estos centros son gestionados por empresas privadas bajo gestión pública, consorcios público-privados, gestión pública (dependientes de los municipios o de los gobiernos autónomos), o gestión privada. Un problema reincidente han sido las condiciones de trabajo del personal sanitario. En Suecia, en estas instituciones para ancianos, que son en parte de propiedad privada o dependientes de las municipalidades, "el personal suele ser pagado por hora, menos remunerado, menos educado y más joven" ha declarado Ingmar Skoog, director del Centro de Ancianos y Salud de la Universidad de Gotemburgo ${ }^{44}$. En Finlandia, estos profesionales están protegidos por convenios colectivos, mientras que, en Suecia, afirman "los que cobran por hora no reciben su salario si se quedan en casa con síntomas leves", como se indica en las instrucciones. En Noruega no se ha apreciado ninguna representación excesiva entre los extranjeros $^{45}$.

3) Propagación en los barrios y áreas económicamente más desfavorecidos. En el caso de

\footnotetext{
44 Gestión, Suecia y la estrategia "outsider" contra el coronavirus, 11 mayo 2020. 11de mayo de 2020, https://gestion.pe/blog/te-lo-cuento-facil/2020/05/suecia-y-la-estrategia-outsider-del-coronavirus.html/ 45 lbid.
} 
Suecia, en Estocolmo, es estos barrios es donde reside la mayoría de las personas de origen inmigrante, están hasta tres veces más afectados por la epidemia que el resto de la capital. Respecto a los inmigrantes y refugiados que viven en las periferias de Estocolmo, el gobierno ha mostrado "una preocupante falta de conocimiento o de interés" por parte de las autoridades sanitarias hacia estas poblaciones, cuyo comportamiento social es a veces diferente ${ }^{46}$.

4) Los impactos sociopolíticos en todos los países europeos están por ver, aunque serán profundos. Durante la crisis sanitaria ya han tenido lugar numerosas protestas en Berlín y otras ciudades alemanas, tanto por grupos de extrema derecha como de extrema izquierda. Desde intelectuales de la izquierda extraparlamentaria, ultraderecha y neofascistas, hasta defensores de las teorías de la conspiración, están llevando a cabo una atípica crítica contra la gestión de la pandemia en Alemania, donde cada sábado se convocan concentraciones en contra del poder político, ya que consideran que se están aprovechando de la crisis para poner en jaque la democracia. En España o Italia grupos conservadores se han manifestado al cuestionar la eficacia del gobierno.

Es todavía temprano e incierto hasta dónde y en qué extensión se producirán los cambios en las administraciones públicas y en su relación con la gobernanza del modelo u orientación del Estado. Tan solo futuras observaciones empíricas podrán descifrar esta incógnita.

\section{Referencias bibliográficas}

Angell, I.; Demetris, D. Science's First Mistake. Delusions in Pursuit of Teory, New York, Bloambury Academic, 2010.

AKTUELLT, 9 april, 2020. Disponible en: <https://www.svt.se/nyheter/utrikes/norskafolkhalsodirektoren-for-tidigt-saga-att-man-lyckats>_Acceso: 14 mayo, 2020.

ARCGIS. Johns Hopkins CSSE, fecha, 17 de mayo de 2020.

Attour, A.; Chaupain-Guillot, S. Digital Innovations in Public Administrations: Technological or Policy Innovation Diffusion? Journal of Innovation Economics \& Management, n.31, 2020. Disponível em:

<https://ideas.repec.org/a/cai/jiedbu/jie_pr1_0061.html> Acceso: 14 mar. 2020.

BBC NEWS. Alejandro Millán, 21 de marzo de 2020, Coronavirus: ¿por qué Alemania tiene un número tan bajo de muertos por covid-19 en comparación con otros países?

\footnotetext{
${ }^{46}$ France 24. Frente a un balance alarmante por el coronavirus, el modelo sueco de tambalea, 16 abril 2020 Declaraciones de Gina Gustavsson. France 24. https://www.france24.com/es/20200416-frentea-un-balance-alarmante-por-el-coronavirus-el-modelo-sueco-se-tambalea
} 
BECK, U. La sociedad del riesgo. Hacia una nueva modernidad. Barcelona: Paídos Ibérica, 1998.

CAIXABANK. Álvaro Leandro; Adriá Morron, Políticas económicas frente a la COVID-19: ¿se romperán las fronteras de lo imposible? Disponible en: <https://www.caixabankresearch.com/politicas-economicas-frente-la-covid-19-se-romperanlas-fronteras-de-lo-imposible> Acceso: 22 mayo de 2020.

CORONAVIRUS COVOD-19 Global Cases by the Center for Systems Science and Engineering (CSSE) at Johns Hopkins University (JHU). 2020.

DAGENS, NYHETER. Stockholm, Det nya coronaviruset / covid-19, 20 mars 2020. Disponible en: <https://www.dn.se/om/det-nya-coronaviruset/> Acceso: 1 abril, 2020.

Der TAgesspiegel. Neue statistische Auswertung bestätigt alten Verdacht. https://www.tagesspiegel.de/wissen/drosten-studie-ueberarbeitet-neue-statistischeauswertung-bestaetigt-alten-verdacht/25882680.html Acceso:1 abril, 2020.

DEUTSCHLANDFUNK KULTUR. Forderung nach mehr Kompetenzen für den Bund. Disponible en: https://www.deutschlandfunkkultur.de/corona-pandemie-forderung-nach-mehrkompetenzen-fuer-den.1008.de.html?dram:article_id=472312 Acceso: 1 abril, 2020.

EL PAís, 21 de mayo de 2020, en: <https://www.deutschlandfunkkultur.de/corona-pandemieforderung-nach-mehr-kompetenzen-fuer-den.1008.de.html?dram:article_id=472312> Acceso: 28 mayo, 2020.

EL PAís, Espanha e Coreia do Sul, exemplos opostos de controle epidemiológico do coronavírus, 16 de marzo de 2020, en: <https://brasil.elpais.com/sociedade/2020-0316/coreia-e-espanha-exemplos-opostos-de-controle-epidemiologico-do-coronavirus.html> Acceso: 3 mayo, 2020.

EL PAís, Economía, 5 de mayo de 2020. Acceso: 9 de mayo de 2020.

EuRopean CENTRE for Disease PREVEntion AND Control (ECDC). <https://www.ecdc.europa.eu/en/geographica-distribution-2019-ncov-cases> Acceso: 18 de mayo de 2020.

EURONEWS, 6 de mayo de 2020. <https://es.euronews.com/2020/04/16/el-modelo-suecofrente-al-coronavirus-empieza-a-hacer-aguas-ante-el-aumento-de-fallecidos $\geq$ Acceso: 9 mayo 2020.

EURONEWS, 6 de mayo de 2020. <https://es.euronews.com/2020/04/16/el-modelo-suecofrente-al-coronavirus-empieza-a-hacer-aguas-ante-el-aumento-de-fallecidos> Acceso: 14 mayo 2020.

FINANCIAL TIMES, 2 de marzo de 2020, Political divisions deepen Spain battles coronavirus. Acceso: 14 mayo 2020.

FRANCE 24. Gina Gustavsson, 16 de abril de 2020.

$<$ https://www.france24.com/es/20200416-frente-a-un-balance-alarmante-por-el-coronavirusel-modelo-sueco-se-tambalea> Acceso en 2 de mayo de 2020.

FRANKFURTER RUNDSCHAU, Klaus-Dieter Frankenberger, en 22 de abril de 2020. Frankfurter Allgemeniner Zeitung, 25 abril 2020. "Tödliche Missstände im System”. 
<https://www.worldometers.info/coronavirus/\#countries.> Acceso 12 mayo 2020.

GESTIÓN, en 11 de mayo de 2020, <https://gestion.pe/blog/te-lo-cuento-facil/2020/05/sueciay-la-estrategia-outsider-del-coronavirus.html/> Acceso: 14 mayo, 2020.

HSBC Global Research Report. 2020. Disponible en:

<https://www.research.hsbc.com/C/1/1/320/gjvcpRH> Acceso: 12 mayo, 2020.

INSTITUTO COORDENADAS. De gobernanza y economía aplicada, Jesús Sánchez. Disponible en: <https://www.institutocoordenadas.com/es/analisis/estrategia-alemania-gestion-covid-19sistema-sanitario-eficiencia_20063_102.html>

Istituto di Reserce Sulla Publica Administrazione, Hilde Caroli Casavola, I collaboratori dei parlamentari, 2014. Disponible en:

<https://www.irpa.eu/pubblicazioni/rapporti-irpa/> Acceso: 22 mayo, 2010.

JIMÉNEZ ASENSIO, R. Empleo público 2020-2030 (1): Desafíos múltiples en un escenario de crisis (I), abril, 2020, <https://gestores-publicos.blogspot.com/2020/04/empleo-publico-20202030-1-desafios.html> Acceso: 7 mayo, 2020.

KNODT, E. Foreword. In: LUHMANN, N. Social Systems. Stanford: Stanford University Press, 1995.

LA Cour, A.; PhILIPpoulos, A. Luhmann Observed. London: The Palgrave Macmillan, 2013.

LA VANGUARDIA. La arriesgada normalidad sueca. Acceso: 31 marzo 2010.

LA VANGUARDIA. Acceso en: 7 marzo 2020.

LIBRE MERCADO 5, abril, 2020, <https://www.libremercado.com/2020-05-04/coronavirusinstituto-coordenadas-atribuye-la-gestion-de-alemania-a-su-sistema-sanitario-1276657011/> Acceso: 22 mayo, 2020.

LA TERCERA. 13 abril. <https://www.latercera.com/la-tercera-pm/noticia/anders-tegnell-elepidemiologo-detras-de-la-polemica-estrategia-de-suecia-contra-elcoronavirus/wdyjfuk4pzgafiq5vc7ocluyr4/> Acceso: 12 mayo, 2020.

LEO NOTICIAS. <https://www.leonoticias.com/internacional/union-europea/envidia-sueca-rigor20200424183308-ntrc.html?ref=https\%3A\%2F\%2Fwww.google.com.br\%2F> Acceso: 12 mayo, 2020.

LUHMANN, N. Sociología del riesgo. México: Universidad Iberoamericana/ITESO, 2006.

LuHmanN, N. Sistemas sociais. Esboço de uma teoria geral. Petrópolis: Edit. Vozes, 2016.

MOLdASCHL, M.; MANGER, D. Institutionelle Reflexivität in der öffentlichen Verwaltung. In: MOLDASCHL, M.; MANGER, D. (Org.). Im Spiegel der Organisation. Innovationsfähigkeit durch institutionelle Reflexivität, 2016. p. 63-86.

OUR WORLD IN DATA, Oxford. Fecha: 13 junio, 2020, $<$ https://ourworldindata.org/grapher/total-confirmed-deaths-of-covid-19-per-million-people-vsgdp-per-capita?xScale=linear\&country=DNK DEU NOR> Acceso: 15 junio, 2020. 
OUR WORLD IN DATA, Oxford. Fecha: 15 junio <https://ourworldindata.org/grapher/totalcases-covid-19?country=owid_wrl dnk deu ita nor esp swe> Acceso: 15 junio, 2020.

OUR WORLD IN DATA, Oxford. Fecha: 15 junio <https://ourworldindata.org/grapher/totalconfirmed-cases-of-covid-19-per-million-people?region=Europe> Acceso: 15 junio, 2020.

OMS GPMB. Un mundo en peligro. Informe anual sobre la preparación mundial sobre las emergencias sanitarias. Junta de Vigilancia Mundial de la Preparación, 2019.

OMS 2020, Situation report n. 10. Disponível em: <https://www.who.int/docs/defaultsource/coronaviruse/situation-reports/20200130-sitrep-10-ncov.pdf?sfvrsn=d0b2e480_2> Acceso: 7 abril 2020.

PFARMA.COM.BR, Fabio Reis, 14 mayo 2020, Estudo de caso: Suécia e o novo coronavírus, disponible en: <https://pfarma.com.br/coronavirus/5612-suecia-covid19.html> Acceso: 3 junio, 2020.

REDACCIÓN MÉdICA. Disponible en: $<$ https://www.redaccionmedica.com/secciones/sanidad-hoy/espana-cuenta-con-la-mejorsanidad-el-mundo-segun-el-foro-economico-mundial-8476>. Acceso: 27 febrero, 2020.

RTVE, Radiografía del coronavirus en residencias de ancianos: más de 19.400 muertos con Covid-19 o síntomas compatibles, 15 junio 2020, disponible en:

<https://www.rtve.es/noticias/20200615/radiografia-del-coronavirus-residencias-ancianosespana/2011609.shtml> Acceso: 9 marzo, 2020.

SUECIA. Governement Office of Sweden 2020. Disponible en: <https://www.government.se/> Acceso: 26 mayo, 2020.

TAIT, A.; RICHARDSON, K. (Edit.). Complexity and Knowledge Management. Understanding the role of knowledge in the Management of the Social Networks. Charlotte: IAP, 2009.

TAGESSPIEGEL. <https://www.tagesspiegel.de/wissen/drosten-studie-ueberarbeitet-neuestatistische-auswertung-bestaetigt-alten-verdacht/25882680.html> Acceso: 22 marzo, 2020.

THE CONVERSATION, 20 march, 2020. Disponible en: <https://theconversation.com/que-es-lainmunidad-de-rebano-y-por-que-reino-unido-confia-en-ella-frente-al-coronavirus-134175> Acceso: 3 junio, 2020.

UNHERD. Which epidemiologist do you believe? The debate about lockdown is not a contest between good and evil. Disponible en: <https://unherd.com/2020/04/which-epidemiologistdo-you-believe/> Acceso: 22 mayo, 2020.

VIDAL, J. Governança democrática. Par uma nova coordenação da sociedade. Rio de Janeiro: Tirant, 2019.

VIDAL, J. Teorías neosistémicas y administración pública: posibilidades organizacionales y regulativas, Revista del CLAD Reforma y Democracia, n. 75, oct. 2019, p. 77-110.

Disponible en: <http://old.clad.org/portal/publicaciones-del-clad/revista-clad-reformademocracia/portal/publicaciones-del-clad/revista-clad-reforma-democracia/articulos/075octubre-2019> Acceso: 12 junio 2020.

WORLDOMETER. Disponible en: <https://www.worldometers.info/coronavirus/> 
VRsP

Josep Pont Vidal

http://orcid.org/0000-0002-6214-6895

Profesor de Teoría de las Organizaciones, Administración Pública y Teoría Sociológica en la Universidad Federal de Pará (UFPA).

E-mail: joseppontvidal@gmail.com 